\title{
THE PAST AND FUTURE OF THE SOCIETY.
}

\section{ADDRESS DELIVERED BEFORE THE AMERICAN MATHEMATICAL SO-} CIETY AT THE ANNUAL MEETING HELD DECEMBER 28, 1894.

BY DR. EMORY MCCLINTOCK.

HAVING been requested by the Council to address the Society on retiring from the presidency, it has appeared to me that I must choose between the discussion of the position and prospects of some branch of mathematics with which I may be familiar and a more general and discursive review of the present position and future prospects of our Society. I have, after some hesitation, chosen the latter subject. It seems desirable, on the whole, that there should be made at this time some permanent record, however slight, of the steps by which so large and flourishing a society has come together, and of the views concerning its present scope and the hopes concerning its future possibilities which are entertained by those who have hitherto been most immediately concerned in the conduct of its affairs.

The New York Mathematical Society, originating in 1888, was at first not much more than a small mathematical club meeting periodically at Columbia College. The first meeting was called by a circular signed by three young men. The number of those who could be expected to attend these meetings was not great, but all who were able and who were sufficiently interested to do so were invited to join the Society. It was fortunate in securing for its first president Professor Van Amringe, distinguished alike by scientific attainments, official eminence, and administrative ability. The professor of astronomy at Columbia was also active in it from the first. The meetings of the young Society were, as I am informed (for at that time I did not reside in New York), attended with more than interest, I might say with zeal. The three who called the Society into being may, without invidiousness, be mentioned as having aided materially in the prosecution of its work. One of these of course need not be named to you. $\mathrm{He}$ has served from the beginning as secretary, and again as the leading member of the publication committee. It is no flattery to him to say that the growing energies of the Society must at various stages have become chilled or misdirected, except for his comprehensive intelligence and untiring industry. Another was our former treasurer, now absent from the country. Still another has been elected by you to-day to the office of librarian. The meetings were, as the ordinary meetings still are, held at Columbia College, and at that time the majority of the members of the Society were 
connected with that institution. The President, after two years' service, fearing that the continuance of a representative of that college as presiding officer would tend to hamper its usefulness, proposed the election of a new president not connected with any college. It was in this way and for this reason that you honored me with the post from which I retire to-day. It is not improper for me to add that I am myself an outspoken believer in the doctrine of rotation in office, and that I was only prevented from retiring at an earlier period by urgent representations concerning the presumed welfare of the Society, at a time when all were not yet fully agreed upon the expediency of changes which have since taken place.

The Society was therefore distinguished from all other American mathematical clubs or associations by two circumstances: it was formed in and took the name of the largest city of America, and it was distinctly understood to be unconnected with any institution of learning. Suggestions came to be made that its usefulness would be decidedly increased by the publication of a periodical journal. Consideration of these suggestions by the Council led to the establishment of the Society's BuLLETIN, with the nature and scope of which you are all familiar. It was decided to be inexpedient to publish original investigations, that field being already occupied by successful American periodicals. 'To meet the expense of the publication, the fees of the members were somewhat increased, and for the same reason, as well as to extend the usefulness of the Society, well-known mathematicians in all parts of the country were invited to become members. That this movement towards enlargement was judicious and timely was proved at once by the rapid growth of the membership, which since the middle of 1891 has included a large proportion of the prominent mathematicians of the United States and Canada. As the Society thus became in reality an association of American mathematicians as a body, the change of name effected this year was only a natural sequence. Finally, the result of the change of name has been that a number of persons, including several of the highest repute, who had not previously joined the New York Mathematical Society, regarding it as a local organization, have connected themselves with the American Mathematical Society; and I need hardly say that, if any one of prominence still holds aloof, from inattention or otherwise, his entrance at any time as a member will be greeted with a hearty welcome.

It is said that when the London Mathematical Society was organized there had been no previous example of a similar organization, and that fears were felt and expressed that its management might naturally drift into the hands of a few 
having time and energy to give to its affairs, and that there might thus be serious danger of its falling into the control of a clique. The lapse of time has developed the fact that the leading members of that society have been men of broad views, unusually free from personal prejudice and quick to recognize talent wherever displayed. We may almost conclude from the history of that society that proficiency in the science of mathematics is distinct evidence of a well-balanced mind. It may be doubted whether an equally numerous body of poets or musicians could have held so successfully on its course during so many years. It is of course impossible to predict that the management of our own society will be equally prudent, energetic, and successful during an equal period to come. All that can be said at present is that not a trace of personal self-seeking on the one hand or of personal prejudice on the other hand has as yet become visible in our councils. One single motive has thus far been conspicuous among all who have interested themselves in the Society: a strong belief in its prospective usefulness combined with an earnest desire to further its success.

'Thus far I have spoken only of the progress of the organization as such. The organization, however, is merely the framework. It has certain living objects, and even during its period of formation and growth it has been distinctly successful in promoting those objects. I have spoken of objects; the Constitution, however, reminds me that there is but one object: to encourage and maintain an active interest in mathematical science. It is, however, possible to subdivide this very general statement of the aims of the society. In order to encourage and maintain an interest in mathematical science, we may say, then, (1) that mathematicians must be brought to know more about each other and concerning each other's work; (2) that their number must be increased by the encouragement of the study of the higher mathematics among the young; (3) that information should be disseminated fully and speedily concerning mathematical publications abroad as well as at home; (4) that, as regards the more important of such publications, competent critics should be induced to write and publish papers descriptive of their contents and indicating their merits or defects; (5) and that every member of the Society should be stimulated to the most successful effort possible in his own line of mathematical labor, whatever it may be. This subdivision is not presented as scientific and exhaustive. Others would doubtless make variations of their own; and it is certain that the separate points I have indicated are not mutually exclusive. I mention these several objects merely as they occur to me for the purposes of this occasion. 
That by entering the Society and receiving its monthly BuLLETIN the mathematicians of the United States and Canada have been and are brought to know far more about each other and concerning each other's work than they ever knew before or could possibly have known otherwise, is obvious to all. The mere list of members, which conveys to each of us the names, addresses, and occupations of all the rest, would alone justify this statement. The BuLlexis, with its lists and reviews of new books, together with many notes concerning the higher mathematical work of different institutions, has afforded much additional information, and it may be expected that further experience will enable its conductors from time to time to add to its usefulness in this direction.

While the Society is not directly concerned in encouraging the study of the higher mathematics among the young, its indirect influence in that direction has undoubtedly been felt, and must be felt increasingly as time goes on. Years ago, when the present century was much younger, the course of stuảy in our colleges was so arranged as to give a large proportion of the time of the undergraduates to the study of mathematics. Subsequently the tendency in colleges having uniform courses of study was to cut down the number of hours given to this science, as well as to the classics, and to parcel out the time among the modern languages and various sciences. It is believed that even already the organization, the meetings, and the publications of the Society have, by the effect of numbers in association, perceptibly strengthened the tone of the mathematical departments of many institutions of learning and assisted in enabling them, more or less successfully, to stem the hostile tide of sentiment to which I have just referred. I say "assisted," for other agencies, especially the journals, have done great good. 'That the dissemination of knowledge concerning the gigantic strides lately made and still making in mathematical science must in the future have the same favorable effect to an even greater extent is not to be doubted.

As to the next point in my list of objects, I need hardly mention to you that the Society has succeeded and is succeeding in disseminating information fully and speedily concerning mathematical publications abroad as well as at home. In addition to this general statement, for the proof of which we need only refer to the monthly numbers of the BuLletin, I may recall to you that the Society is at this moment engaged. in publishing, at its own expense, supplemented by personal subscriptions, one of the largest and most important volumes ever published containing nothing but original investigations; namely, the extensive and very valuable collection of papers - mostly by European authors-prepared for and presented 
to the Mathematical Congress of 1893 held in connection with the World's Fair at Chicago.

Again, considerable success has been attained in inducing competent critics to write and publish papers descriptive of the contents and indicating the merits or defects of the more important current mathematical publications in all countries. In this respect it is hoped that the usefulness of the BuLleTIN, already recognized, will be largely augmented as time goes on. You have to-day strengthened the Publication Committee by the addition of a third member of tried capacity. The Committee depends for its critical papers upon the cooperation of other members of the Society, and it is especially pleased to receive voluntary offers of such papers from members who have not yet contributed to the BuLLETIN. It is to this resource as much as to any other that we must look for the enlargement and improvement of the BuLLETIN. The Committee must be aided freely by the presentation of an increasing amount of material from which to choose; and I use this occasion to urge upon each member that he take every opportunity consistent with other engagements to impart to his fellows the historical and critical results of his own reading in any special branch, and particularly in connection with any new and important work recently published in that branch. The well-known saying of Bacon cannot be too constantly before our minds: "I hold every man a debtor to his profession, from the which as men of course do seek to receive countenance and profit, so ought they of duty to endeavor themselves by way of amends to be a help and ornament thereunto."

Finally, and I might say above all, it is the object of the Society that every member should be stimulated to the most successful effort possible in his own branch of mathematical labor, whatever it may be; whether it be in teaching, or writing, or original investigation, or in any combination of these lines of activity. The investigator must also be a writer; the writer may present his own investigations, or comment upon or summarize or write the history of those of others, or elaborate a treatise or text-book upon some special subject; but whoever may investigate, and whoever may write, it is the lot of almost all of us in one way or another to teach. For this reason it is plain that this Society is, and must always remain, a society of teachers. Any tendency to restrict its usefulness solely to the paths of investigation and publication should, for every reason of prudence and wisdom, be resisted. 'The management of any organization which does not commend itself to the great majority of those interested must not indeed necessarily end in failure, but must certainly fail of producing the most appropriate, the most useful, and therefore the best 
results. While, however, expressing this general opinion, I would by no means be understood to disparage the work of the writers and investigators. Not every teacher, however successful, feels impelled to write for publication, and not every writer has time and facilities for original investigation ; yet we all of us take pride in such work when done by others, and we all of us, as members of the Society, feel that it would fail of its highest objects if it did not encou rage in every way the production of good papers and books and, above all, the prosecution of original discovery.

In encouraging the writing of books, as distinguished from the prosecution of original research, the Society can do little except indirectly, by increasing the possible demand for such works. The need of what we may call advanced text-books giving, as far as possible, summaries of existing knowledge in the several higher branches has long been felt, and of late years has to some extent been supplied. Some of these fields, however, are still open; and as time goes on, fresh books, to take the place of those now fresh, will still be wanted; for our science is in all points, even those sometimes regarded as most stationary, in a condition of advancing evolution. It is, if you please, the same old oak, but what formerly were twigs are now sturdy limbs, and what now are tiny stems may soon be recognized as vitally important branches. As to the making of thorough and systematic books on mathematical subjects, it has before now been remarked that the task is really more difficult, for some at least, than that of working up original papers. Some of the reasons for this were clearly stated by Mr. Glaisher in his presidential address in 1886 before the London Mathematical Society. I recall the case of a friend who at one time began the preparation of a summary of knowledge in a special field; but he had not gone far before he found such temptations in the way of unifying theories or bridging over gaps that the result was the production of two or three contributions to the journals and the abandonment of the book. We must, I think, accord unusual honor to those who apply themselves successfully to the task, more arduous every year as the mass of original work rolls up, of summarizing and condensing into clear bodies of doctrine all existing important discoveries in special fields of mathematical labor, certainly without hope of pecuniary reward and usually without prospect of any wide circle of readers.

As yet the Society has done little towards the encouragement of writing and investigation. 'The existing well-known and successful journals maintained, whether by a great university, by scientific societies of a general character, or by the generous efforts of individuals, have afforded opportunities for the publication of extensive papers with which the Society's 
Bulletin is not intended to compete. For much the same reason those of its members who have been personally solicited to give their aid have been appealed to for contributions to the BULLETIN rather than for original papers to be read and discussed at the meetings. It is hoped that, as time goes on, the members of the Society will become more and more accustomed to present their original papers for reading at the meetings before publication. It may perhaps also be expected that a closer connection may be developed between the reading and the publication of such papers, whereby, on the one hand, perhaps, editors of journals may, as members of the Council or otherwise, have some preliminary oversight of the acceptance of papers for reading, and whereby, on the other hand, the acceptance of a paper for reading shall insure its speedy publication.

While the Society can thus do little directly to encourage the writing of important treatises, it can and should, without doubt, do much to stimulate original research. Original discovery has always been recognized as the quickest and surest road to distinction. A permanently valuable paper read and discussed at a meeting of the Society becomes an immediate object of interest to those who attend; the subsequent record of the reading in the BuLLETIN, supplemented, perhaps, by a brief abstract, excites a still wider interest among the membership at large; and in this way many of the readers are prepared to welcome the publication of the paper when it appears. There are-apart from the institution of medals or prizes, which would be within the Society's province-many other ways in which, directly or indirectly, the intluence of the Society may be felt in turning the attention of individuals to the importance of original work. And as some slight contribution towards this desirable end, I shall close this address with a few remarks and suggestions intended more particularly to reach those members of the Society whose attention is turning in this direction, but who have not as yet produced original papers. If in doing so I happen to give good advice, particularly as regards style, which I have not always succeeded in following myself, I trust that I may be favored with the same kindly personal consideration as is customarily accorded to an emaciated physician or to a stammering professor of rhetoric. Yet as to the style in which a mathematical paper should be written, as distinguished from good English style in general, there is not really very much to be said. Such papers should contain good English, and enough of it. Obscurity, above all things, should be avoided. T'he printer should not be annoyed unnecessarily by complicated fractions and other things difficult to print. Phrases and symbols familiar to the writer, but not necessarily familiar to 
his readers, should not be introduced without explanation. Such phrases and symbols can always be explained by taking the time and trouble; and though the paper be made somewhat longer, it becomes far more satisfactory. It is of course possible, especially if one has not much to say, to err in the opposite direction by diffuseness and verbosity. The golden mean lies in the distinct explaining of every symbol, of every phrase not universally understood, and of every step in the discussion in language otherwise extremely concise.

It would doubtless excite a smile were it known that any young man was for the first time saying to himself: "Go to! let me make a discovery." Yet that is what each one implicitly does say to himself who makes any discovery. It is hard to imagine how any new point could occur fortuitously to an investigator not engaged in investigating. No one can tell until he tries whether or not he is fitted for that sort of work. No one can be sure, even though failure come to him after failure, that he shall not later meet with success. One sort of failure, indeed, should convey the most flattering encouragement. It is when a supposed discovery is made, which proves on further inquiry to have been made long before by some one else. The immediate effect is disheartening; and yet the occurrence has established the existence of the power of discovery. When once anything, no matter what and no matter how old, is discovered afresh and originally, the beginner has only himself to blame for any subsequent want of success. It may, in fact, be doubted whether every earnest mathematician who takes pleasure in his work has not in him, to some extent at least, the capacity for discovery. Indeed, any fresh solution of an interesting problem, any new proof of an old proposition, is in itself a piece of original work. Undoubtedly some are born with greater capacity than others; yet no one can tell, without trying, the limits of his own capacity in this direction; and it is probably true in this, as in other lines of effort, that genius consists in an infinite capacity for taking pains.

He who for the first time makes an attempt towards original mathematical research must do so either in pure or in applied mathematics. By far the greater number of papers relate to the former class of investigations; and yet it would seem that greater opportunities for attaining important results lie in the latter direction. We all of us know, in a general way, that many important improvements in pure mathematics are the direct result of efforts connected with practical applications. Our knowledge of the laws of physics is constantly undergoing development. Just now, perhaps the most important improvements are those connected with the laws of electricity, in which some of the members of 
this Society have taken a prominent part. Mr. Walker, in his presidential address of 1890 before the London Society, brought forward numerous instances illustrating the enormous influence of applied mathematics upon the progress of the pure science. 'The numerous illustrations which he adduced should be consulted by every one interested in the applications, and should encourage him to active effort in extending the domain of applied mathematics, and thereby almost necessarily adding to existing knowledge in the region of pure mathematics.

For some reason which no one has undertaken to explain, but probably connected with the much wider dissemination of elementary instruction in pure mathematics as compared with applied, by far the greater number of investigations thus far have related to pure mathematics; and it may be presumed that for some time to come this disproportion will continue. In other words, our young mathematician who says to himself that he will make a discovery is most likely to confine his efforts to that in which he has been most thoroughly instructed, and with which he is therefore the most familiar - the pure science. How, then, is he to set about it? One way, and a most satisfactory one, would be to take part in some such seminar as that at Göttingen, described some time since in our BullETIN. Another quite similar method is to begin by assisting some active investigator, and carrying out his suggestions faithfully. The impulse given to a number of our best men in this way by Professor Sylvester when he was in this country is well known to us all. On the other hand, any attempt at collaboration between two equals would seem almost certainly predestined to failure. Though exceptions are well known, it is really rare to find any fresh and important development in a paper worked up by two friends of equal skill, and still rarer to find a succession of papers by the same pair of authors. Good practice, however, can be had in correspondence between two friends on some fresh subject, each sharpening the mind of the other, provided the correspondence be carried on as a matter of growing interest between the two, rather than for the purpose of producing a joint publication. As a rule, however, the young discoverer works alone, and he will most likely find, before he gets to the publishing stage, that his first discoveries have been made earlier by others. He must choose his subject according to his own taste. Usually he will be led most easily to some fresh result if he reads and digests with keen interest the latest publications of others upon some growing subject. $\mathrm{He}$ may, perhaps, perceive that one of these papers has not exhausted all the possibilities; or he may, by an alteration in the point of view, find himself enabled to obtain the same 
result by a much shorter and more satisfactory process. $\mathrm{He}$ must not fear that he is giving his mind to a subject too trivial. No matter how slight the addition which he makes to the sum of knowledge, it is yet an addition; and unless it is superseded by the doing of the same thing by some one else in a better manner, it is a permanent contribution to science. Some are helped greatly, at times, by working first on some numerical illustration of the problem in hand; others, again, by a preliminary geometrical representation; and the first path to any discovery is not usually the best. It is sometimes supposed that the mass of original work done in so many countries and published in so many languages makes it likely that any ordinary piece of work will be overlooked in the great mass. Nevertheless, litera scripta manet; and what may now seem an unimportant addition to an unimportant branch may probably one day, when that branch is no longer unimportant, and when its special history comes to be itself a topic of discussion, receive its due recognition. Meantime, every little helps. The most trifling addition to the actual sum of knowledge will be at least useful as a step to aid the next investigator; but whether important or unimportant, whether appreciative recognition comes or not, whether others are helped or no one takes notice, there is a degree of personal pleasure in the mere fact of origination which is the just and certain reward of every piece of successful investigation.

\section{NOTE ON A MEMOIR IN SMI'TH'S COLLEC'TED PAPERS.}

BY PROFESSOR CAYLEY.

Among the most noticeable papers in the Collected Mathematical Papers of H. J. S. Smith we have the hitherto unpublished "Memoir on the Theta and Omega Functions," XIIII (vol. 2, pp. 415-623), written in connection with Dr. Glaisher's Tables of the Theta Functions and originally intended as an Introduction thereto. It appears that in 1873 or $1874 \mathrm{Dr}$. Glaisher asked him, as a member of the British Association committee for the calculation of the Tables, whether he would contribute an Introduction. His reply was that he did not see his way to writing anything appropriate to the tables themselves, but that he "could say something with respect to the constants at the head of the pages." These constants were $K, K^{\prime}, E, J, J^{\prime}$, etc., the numerical values whereof were given for every minute of the modular angle. The memoir grew in extent, and it was finally decided that it should follow these yet unpublished tables with the before-mentioned title, 